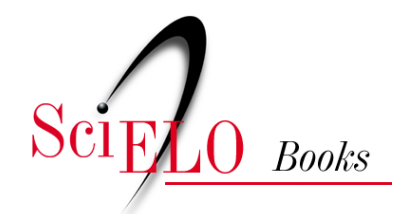

EDUFU

\title{
Da apropriação estética das anomalias
}

\author{
José Tonezzi
}

TONEZZI, J. Da apropriação estética das anomalias. In: FLORENTINO, A., and TELLES, N., eds. Cartografias do ensino do teatro [online]. Uberlândia: EDUFU, 2008, pp. 145-153. ISBN 978-857078-518-3. https://doi.org/10.7476/9788570785183.0015.

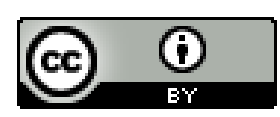

All the contents of this work, except where otherwise noted, is licensed under a Creative Commons Attribution 4.0 International license.

Todo o conteúdo deste trabalho, exceto quando houver ressalva, é publicado sob a licença Creative Commons Atribição $\underline{4.0}$.

Todo el contenido de esta obra, excepto donde se indique lo contrario, está bajo licencia de la licencia $\underline{\text { Creative Commons }}$ Reconocimento 4.0. 


\section{DA APROPRIAÇÃO ESTÉTICA DAS ANOMALIAS}

José Tonezzi

Refletir sobre o ensino do teatro e a formação do ator já se apresenta comumente como algo de extrema complexidade. $\mathrm{O}$ que dizer então sobre as condições dadas para esse debate num regime de exceção, como é o caso de atores ou candidatos a atores que apresentem algum tipo de disfunções, sejam elas de caráter físico, sensitivo ou neurológico? Assim, cumpre esclarecer que, embora o presente estudo tenha por objeto o trabalho cênico envolvendo anomalias, o envolvimento deve ocorrer no âmbito da competência estética, daí a importância de que a abordagem não considere projetos necessariamente concebidos para deficientes ou que tenham como premissa a participação deles.

Quando se destaca o termo apropriação estética se quer significar o apossar-se das disfunções pelo fazer artístico, de maneira a adequá-las e tornar a elas ou aos seus sintomas instrumentos para o exercício e a experiência estética, no caso, da arte do teatro. Assim, diferentemente de um caráter terapêutico ou pedagógico, o ensejo é pensar o procedimento artístico que desconsidere possíveis anormalidades como empecilho ou impedimento mas, ao contrário, perceba-os como matéria de efetiva criação e experiência estética, sendo correto afirmar que se trata de uma abordagem sobre a acepção cênica das disfunções. Mesmo assim, na parte final do texto, tenta-se uma referência mais específica ao ensino teatral nesse âmbito.

De início, vale uma breve alusão à própria evolução da cena ocorrida no século XX, quando o espetáculo teatral passa a ser tido cada vez mais como um objeto distinto e independente do texto dramático. Este, em geral valorizava a composição de personagens previamente concebidas, quase sempre requerendo e estimulando o trabalho de atores com biótipos semelhantes. As exceções ficavam por conta de eventuais personagens exóticos ou estereotipados, levados à cena pela camuflagem corporal e pela maquiagem desses mesmos atores. O que se pode afirmar é que, até então, as anomalias eram vistas comumente como bizarrices, admitidas apenas no seio de determinados espetáculos e atividades de entretenimento, como o circo, onde eram apreciadas como objeto de curiosidade.

Com a autonomia da cena em relação ao texto, novos procedimentos começam a ser percebidos, dentre os quais, uma criação com base na dinâmica e nas características corporais do artista. Essa transformação se dá de forma gradual e se mostra muito mais como estratégia necessária à sobrevivência e evolução de ambos, texto e cena, dando conta de uma nova realidade que parece impor-se ao papel 
desempenhado pelo próprio teatro. O desafio começa na complexidade cada vez maior com que o mundo e a vida moderna passam a se apresentar e, aos poucos, mesmo os mecanismos de um drama absoluto calcado em questões intersubjetivas dos personagens não darão conta das intricadas relações sociais modernas.

$\mathrm{O}$ aparecimento da performance ou body art, em princípio restrita às artes plásticas, logo influenciará nas diversas outras formas de expressão, dentre as quais o teatro. Surgida como resultado de manifestações artísticas ocorridas desde o final dos novecentos, a performance terá importância capital para a incorporação cênica das anomalias, já que nela são enfatizadas justamente a efemeridade e a falta de acabamento da produção. Novas alternativas serão simbolicamente detonadas e inéditas perspectivas serão abertas para a concepção do corpo como matéria significante, o que altera e desestabiliza as relações até então perenes entre a obra e o observador:

O processo comunicacional a nível corporal inclui pressupostos - os códigos culturais compartilhados - e seu valor ilocutório se estende além da zona de consciência do receptor: afeta núcleos profundos, sobretudo no caso de experiências traumáticas como as amputações ou a presença de corpos marcados, tatuados, feridos ${ }^{1}$.

O conceito ganha novos contornos e acaba incorporado por áreas diversas. Para o sociólogo Erving Goffman ${ }^{2}$, performance é toda atividade desenvolvida por um participante em dada ocasião que sirva para influenciar de alguma maneira outros participantes. Interessando-se pela estrutura da experiência individual em todos os momentos da vida social, ele ampliaria ao extremo a concepção para o termo ator, assim denominando todo e qualquer indivíduo a desempenhar "papéis/personagens" que seguem uma trama previamente estabelecida.

A partir dessa premissa, passa a ser possível perceber o elemento performático numa simples intervenção pública de algo inusitado, o que incute o status de performer sobretudo àqueles indivíduos que apresentem condições alteradas de expressão ou comportamento. Pode-se afirmar, inclusive, que as condições pré-estabelecidas de aparência ou conduta que o alçam do meio comum favorecem no indivíduo fora de padrão a criação de um estado de surpresa, muitas vezes só alcançável pelo ator não deficiente através de um efetivo trabalho de preparação. E é justamente o que se denota como surpreendente que, na performance, normalmente atrai o interesse e a conseqüente atenção do espectador:

[...] in order to attract and direct the spectator's attention, the performance must first manage to surprise or amaze; that is, the performance must put into effect disruptive or manipulative strategies which will unsettle the spectator's expectation both short and long term - and, in particular, her/his perceptive habits ${ }^{3}$.

\footnotetext{
${ }^{1}$ GLUSBERG, Jorge. A arte da performance. São Paulo: Perspectiva, 2003. p. 98.

${ }_{2}^{2}$ GOFFMAN, Erving. A representação do eu na vida cotidiana. Petrópolis: Vozes, 1996. p. 191-217.

${ }^{3}$ DE MARINIS, Mario. Dramaturgy of the Spectator. The Theatre Drama Review, New York, v. 31, n. 2 (T114), p. 100-114, Summer, 1987. Tradução nossa. "[...] a fim de atrair e dirigir a atenção do espectador, a performance deve antes conseguir surpreender ou assombrar; isto é, a performance deve fazer uso de estratégias manipuladoras ou destruidoras de maneira a perturbar a expectativa do espectador - ambas a curto e longo prazo - e, em particular, a sua percepção habitual”.
} 
Portanto, as reações e comportamentos previsíveis, inesperados ou mesmo inoportunos que as chamadas disfunções e distúrbios do corpo e da mente ocasionam passam a mostrar-se como fatores que, se eficientemente trabalhados, serão capazes de mobilizar a assistência e mover o exercício da cena. Isso faz com que diretores e dramaturgos se apercebam cada vez mais das anomalias, para extrair-lhes o que de mais performático eles possam ter.

A apropriação estética das condições e particularidades, em si, decorrentes das disfunções que acometem o indivíduo, poderá se dar tanto por parte dele próprio como ser ocasionada e estimulada por quem o orienta ou o dirige cenicamente. Ambos os casos, no entanto, estariam invariavelmente vinculados a uma experiência vivida e compartilhada, pressupondo uma relação de mútua confiabilidade, em que o sujeito esteja inserido num contexto de significação. Fala-se, então, em competência poética para a constituição da cena quando se mune tais pessoas de condições mínimas para que atuem e se desenvolvam. E isto, a partir de um maior ou menor conhecimento e apropriação dos elementos que compreendem a composição e a estruturação dramática.

\section{A experiência de Robert Wilson}

Sem dúvida, diversas iniciativas poderiam ser citadas no que tange ao uso cênico das disfunções, algumas até bem mais recentes, mas o processo de criação desenvolvido por Robert Wilson, sobretudo em seus trabalhos iniciais como diretor, permanece emblemático. É o que acaba, efetivamente, por determinar a própria trajetória de sua arte e abre um novo campo de visão para o teatro ocidental contemporâneo.

Atuando, na juventude, como arquiteto e interior designer, além de pintor, Wilson terá boa parte de sua obra no teatro realizada a partir do contato e cooperação com dois artistas deficientes: os meninos Raymond Andrews e Cristopher Knowles. Coincidentemente, as dificuldades de ambos incidem sobre a linguagem, já que o primeiro é surdo-mudo e o segundo, autista. E é justamente isto que chamaria a atenção do diretor, que vê nessas características a chance de exploração de novas possibilidades de expressão.

Na verdade, ele havia participado de trabalhos dessa natureza já na universidade onde, sob orientação da bailarina Byrd Hoffman, desenvolvia atividades teatrais com crianças cérebro-lesadas. Esse contato, ao que parece, além de ajudá-lo a superar um problema de fala de infância, permitiu-lhe o acesso a uma série de exercícios por ela criados com base nos primeiros estágios da atividade física, cujo intuito seria ativar determinadas células cerebrais daquelas crianças. Neste sentido, Galizia é enfático: "O contato de Wilson com a Sra. Hoffman estimulou seu interesse por terapia com surdos, retardados, autistas, senis e deficientes; porém, mais do que isso, abriu para ele as portas de uma nova visão das artes teatrais"”.

Assim, uma das maiores características de Wilson será justamente sua visão não autoritária do processo criativo. Ao buscar uma forma de acesso ao universo pessoal e ao imaginário, ele está muito mais interessado em aproveitar a expressão

${ }^{4}$ GALIZIA, Luiz Roberto. Os processos criativos de Robert Wilson. São Paulo: Perspectiva, 1986. p. XXI-XXII. 
de cada indivíduo de maneira particular. Ao contrário de um processo tradicional de criação, em que uma nova estrutura de linguagem é normalmente aprendida, o seu performer deve na verdade familiarizar-se e aprofundar o seu próprio vocabulário.

Em Nova Iorque, ele forma e dirige uma companhia que denomina Byrd Hoffman School of Byrds, numa homenagem a sua antiga professora. Todos, exceto um dos integrantes do grupo, eram amadores sendo que alguns, inclusive, foram tirados da rua por Wilson. O trabalho deles, conseqüentemente, era livre de modelos pré-estabelecidos, apresentando modos de comportamento e tipos de fala bastante distintos entre si. Nos workshops experimentais que realiza com o grupo, o diretor estimulava-os a uma criação sem preconcepções estéticas, evitando trabalhar nos moldes do teatro convencional.

Sem dúvida, a colaboração com artistas amadores, diversos deles tidos como deficientes sensorial ou intelectualmente, será um dos meios mais bem sucedidos utilizados por Wilson em sua busca por uma expressão que se pode dizer idiossincrática. $\mathrm{O}$ primeiro deles a contribuir para o seu teatro foi o pintor Raymond Andrews, menino surdo e sem fala que, até conhecer Robert Wilson, nunca havia ido à escola. Excluído do mundo e de suas conseqüentes idéias e normas, Andrews desenvolveu uma genuína e rica vida interior:

He was not only an accomplished visual artist, possessing an extraordinary sense of colour and spacial composition, his paintings also provided Wilson with an entirely original iconography, a network of images that was unique to his imagination ${ }^{5}$.

O principal fruto desta cooperação será o espetáculo "O olhar do surdo", que durava três horas, contava com cerca de cem atores e apresentava cenários gigantescos. Era excepcional não apenas por sua grandiosidade e pelas imagens criadas, mas, sobretudo, pela aparente ausência de lógica, cujo sentido era inacessível ao público. Baseando-se em grande parte nos desenhos e visões de Andrews, que também aparecia em cena, eram trazidas à cena imagens oníricas e figuras tão diversas quanto belas e desconexas, como anões, ossos e animais diversos. Essa multiplicidade de sons e formas era, na verdade, reflexo do mundo e das referências internas de seus criadores, não compartilháveis culturalmente.

Recursos como movimentos em câmera lenta, atividades simultâneas e repetição foram gradativamente tornando-se uma marca do trabalho de Wilson no teatro. É nos limites do dizer que Bob Wilson produzirá, nesse período, espetáculos em que a palavra será minimamente utilizada, passando as imagens e as atividades não-verbais a impor-se sem, no entanto, significar algo específico e pré-determinado, mas, ao contrário, abrindo possibilidades diversas de significação - ou não. Isto, é certo, empresta um sentido polissêmico à cena, pois que a possibilidade do múltiplo, base da polissemia, se constitui justamente pela incompletude.

\footnotetext{
${ }^{5}$ COUNSELL, Colin. Signs of performance: an introduction to twentieth-century theatre. London: Routledge, 1996. p. 182. Tradução nossa. "Ele era não apenas um talentoso artista visual, possuindo um extraordinário sentido de cor e composição espacial, suas pinturas muniram Wilson com uma iconografia inteiramente original, um sistema de imagens que era extraordinário para sua imaginação."

${ }^{6}$ DEAFMAN glance. Criação e direção de Robert Wilson. New York: Byrd Hoffman Foundation, 1970.
} 
Entretanto, a partir de sua colaboração com Christopher Knowles, iniciada em 1973, a palavra passa a ocupar um espaço cada vez maior na obra do diretor norte-americano. Buscando um resultado cênico, Wilson tentará descobrir qual estrutura de linguagem era capaz de permitir a Knowles, um menino considerado autista, expressar-se. Percebe então que sua habilidade no manejo da palavra era de ordem matemática:

O bom da poesia de Christopher é que se trata de matemática e geometria, mas tem a ver com imagens poéticas. Há um sentido de construção e matemática no modo com que as coisas se juntam. Essa é a sua maneira de pensar: Chris tem quase uma obsessão por ordem

Assim, o material verbal utilizado em algumas de suas performances com Knowles baseia-se, sobretudo, nas estruturas lingüísticas geométricas por ele desenvolvidas, em que fragmentos de uma palavra podem ser ditos muito depressa e repetidos de maneira normal ou de trás para frente, o que acaba por criar um padrão visual na mente daquele que ouve:

In using language in anti-sensical ways - breaking the usual ties between a sound/ image and its meaning, or between one word and those which follow it grammatically - Knowles and Wilson elude the formulations of the exterior screen. In doing so, however, they reduce word to raw phonetic or visual material which can then be used to create patterns of a different kind. Knowles and Wilson do not structure their words to generate new meanings; rather, they strip words of their usual meaning in order to build new structures."

A fim de estimular criativamente Knowles, levando-o a travar consigo um diálogo composto de jogos verbais, Wilson fará uso de um procedimento que se repete em diversas das performances que criaram. O recurso seria a evocação de estágios primários do relacionamento entre eles, como se a reativação daqueles momentos bem-sucedidos de comunicação pudesse funcionar como meio de abertura para novas possibilidades de interação e de criação. Assim, na peça longamente intitulada "Um homem louco, um gigante louco, Um cachorro louco, uma urgência louca, um rosto louco", estreada em maio de 1974, a frase "Emily likes the TV", por exemplo, excerto de um diálogo gravado ocorrido entre ambos, servirá como estímulo à improvisação de Knowles, gerando fragmentos de frase, fonemas e sons diversos e repetitivos, como explica Wilson:

Quando dizemos uma palavra há muitas outras coisas acontecendo. No segundo que utilizamos para dizer essa palavra muitos outros pensamentos já passaram por nossas mentes: pudemos experimentar através dos outros sentidos, muitas outras coisas. Eu

\footnotetext{
7 DE LA FALAISE, M. Einstein at the met (an operatic interview). Feb. 1977. Interview. Disponível em: <http://www.robertwilson.com>. Acesso em: 19 jul. 2008.

${ }^{8}$ COUNSELL, 1996, p. 192, tradução nossa. "Usando a linguagem de maneira anti-sensitiva rompendo os laços habituais entre um som/imagem e o seu significado, ou entre uma Palavra e o que a complementa gramaticalmente, Knowles e Wilson transcendem as formulações do mundo exterior. Entretanto, ao fazer isso eles reduzem a palavra a um material fonético ou visual bruto, que então pode ser usado para criar padrões de diferentes tipos. Knowles e Wilson não estruturam suas palavras de modo a gerar novos significados; para além disto, eles despojam as palavras do seu significado habitual para construir novas estruturas."
} 
queria saber como poderia transcrever todas essas outras coisas que se passam, ao mesmo tempo, para o som das palavras. Parecia-me que muitas das coisas que Chris estava fazendo relacionavam-se diretamente com o que ele estava vivenciando?.

Acreditando que há, na linguagem, uma espécie de energia, um elemento que precede o significado tornando possível a comunicação, Wilson observa semelhantes reações entre Knowles e Andrews, percebendo que antes de aprendermos o significado de uma palavra, nós respondemos ao seu som. Conclui que algo muito básico e universal existe na linguagem, tornando-a possível de ser compreendida em qualquer lugar. Para ele, a comunicação pode perfeitamente ocorrer nesse nível e o teatro pode ser a instância privilegiada para esse processo.

\section{Conclusão}

Ampliando-se a discussão para o âmbito do ensino teatral e da formação do ator, é preciso entender que num regime de exceção, como é o caso, o assunto se torna tão importante quanto difícil. Vale, porém, a lembrança de que a arte do ator quase sempre se colocou à margem do que se convencionou chamar "mainstream" vigente. Num passado não tão distante, eram comuns as intervenções da Igreja ou de autoridades civis que impediam as trupes teatrais de se instalar por muito tempo numa mesma cidade. Isso para não falar do tratamento em geral dado à categoria, classificada no mesmo rol de atividades tidas como impuras, ilícitas e imorais. Dono de um modo de vida peculiar e normalmente muito diferente da maioria dos seus contemporâneos, o ator acabava excluído, fosse por inveja, rejeição ou reprovação, tido como um herético aos olhos dos seus contemporâneos. E ainda que o seu estatuto social tenha se modificado e ele já não seja banido como ocorria no século XVII, o comediante ganha uma nova conformidade:

Il est un marginal de societé globale et néanmoins membre d'une communauté réelle [...] A quelques exceptions près, il est en rupture avec son milieu d'origine. Non seulement la precarité financière de l'avenir effraie la famille, mais le 'desordre' de moeurs, conséquence de la profession est encore plus inquiétant. Les préjugés moreax à l'égard des jeunes gens et des jeunes filles qui choisissent une 'vie libre' persitent aujourd'hui sans que l'Eglise ait besoin d'excommunier ${ }^{10}$.

É essa tradicional condição que lhe foi destinada pela sociedade que permite ao teatro mostrar-se como um fértil reduto para a preservação e exercício das diferenças. Isso, no entanto, não exime os seus profissionais de preconceitos ou de desinformação quando o assunto é a diferença no sentido das limitações impostas por disfunções e distúrbios do corpo e da mente.

\footnotetext{
${ }_{9}$ GALIZIA, 1986, p. 79.

10 MOUNIER, Catherine. Devenir comédien. Les Voies de la Création Théatrale, Paris, n. 9, p. 17, 1983. Tradução nossa. «É um marginal da sociedade global e, contudo, membro de uma sociedade real. [...] Salvo exceções, ele está sempre em ruptura com o seu meio de origem. Não apenas a precariedade financeira do futuro assusta a família, mas a desordem dos costumes, conseqüência da profissão, é ainda inquietante. Os prejuízos morais com respeito aos jovens que escolheram uma 'vida livre' persistem ainda hoje, sem que a Igreja tenha a necessidade de excomungá-los.»
} 
Neste sentido, bastante útil e esclarecedor é o conceito implementado pela Organização Mundial da Saúde (OMS), que conceitua distintamente as deficiências, as incapacidades e os impedimentos, comumente tidos sob um único entendimento. Segundo esse critério, uma situação pode decorrer em outra e em ordens diferentes. Uma deficiência visual profunda e precoce, por exemplo, decorrerá em certas incapacidades, dentre as quais a de identificar à distância a forma e a dimensão das coisas, o que por sua vez acarreta como desvantagem a restrição de trânsito do indivíduo pelo mundo e o seu impedimento na realização de determinadas tarefas. Num sentido inverso, algumas desvantagens ou impedimentos (a miséria, por exemplo) podem decorrer em incapacidades (a de domínio da expressão simbólica e manipulação do pensamento hipotético) que, por sua vez, podem levar um observador menos atento de testes a concluir por certa «deficiência» das funções cognitivas do indivíduo.

A partir dessa percepção, tem se buscado reduzir ou remediar as incapacidades com base nas capacidades da pessoa: "Isso implica transformar o olhar dirigido em sua direção: não se trata mais apenas de determinar seus limites e sim, além disso, de ressaltar aquilo de que de fato é capaz"11. Portanto, quando se fala em limitação pode se estar falando também em potencialidades e alternativas, sendo a questão muito mais de atitude diante do fato do que uma simples concessão.

Isso torna fundamental que o indivíduo seja aceito no interior de um grupo de atores considerados "normais" e que o programa tenha em conta e promova as diferenças, realçando justamente as singularidades de cada um, avivadas pela presença de alguém tão distinto. $\mathrm{O}$ fato pode, inclusive, constituir-se como diferencial para um exercício cênico inovador e instigante. Não se trata, porém, de se admitir uma pessoa pela simples razão de possuir algum tipo de anomalia, e sim de promover uma concreta integração daquelas que demonstrem sensibilidade e disponibilidade para a expressão dramática, características perceptíveis a partir de uma sessão de jogos e exercícios.

Em geral, duas ações distintas e complementares se apresentam, sendo a primeira delas a que diz respeito ao reconhecimento e apropriação, em si, das condições e particularidades do individuo, já abordadas anteriormente. A segunda está relacionada à identificação e uso das habilidades por ele adquiridas, graças a uma formação anterior e específica, junto a instituições ou profissionais especializados. Essa condição pressupõe uma cultura assimilada e compartilhada, em geral, no seio de um coletivo, perpetrada por práticas reconhecidas de ensino para deficientes, especialmente os auditivos e visuais. Tais habilidades se valem, em geral, de alternativas que compensem impedimentos relacionados ao uso da linguagem e da comunicação. São códigos e procedimentos técnicos criados de maneira a facilitar a relação e trânsito da pessoa no mundo. Aqui, podem mostrar-se útil ao orientador o acesso e o reconhecimento dos elementos que compõem esse universo, a fim de promover um efetivo intercâmbio de possibilidades e de interesses, a serem transportados para o exercício cênico. Servem de exemplo a linguagem de sinais utilizada pela comunidade de surdos e os procedimentos levados a efeito para a integração social de cegos, como os meios e instrumentos de identificação sonora e tátil.

Para cada caso haverá uma configuração bastante particular, em que a pes- 
soa tem o direito e será capaz, se assim estimulada, de valer-se de meios criativos e originais para uma expressão cênica. Portanto, um efetivo trabalho de reconhecimento, exploração e reorganização esquemática do corpo-voz mostra-se importante para sua restituição como espaço primeiro de automanifestação e relação com o mundo. As práticas devem ser capazes de levá-la a uma (re) descoberta das habilidades intrínsecas à expressão e à comunicação humana, incorporando de maneira dinâmica as suas condições e limitações, o que incorre numa afirmação da capacidade singular de manifestação que cada um possui. Para tanto, importante será reconhecer a validade dos recursos epilingüísticos e metonímicos na expressão e na comunicação, o que recolocará o indivíduo com dificuldade de fala ou de expressão na condição de um interlocutor efetivo, autorizado a processar as informações, reconstituindo-as de acordo com as suas experiências próprias e contextualizando-as de acordo com as suas condições. Portanto, através de simulacros verbais e corporais o sujeito torna-se capaz de ampliar sua capacidade de comunicação, ainda que fora dos padrões normatizados e socialmente tidos como corretos. A produção e uso de gestos e de sons, a articulação de palavras próximas ou similares, que semanticamente contextualizem o enunciado devem, pois, ser estimulados de maneira a integrar o repertório expressivo do indivíduo.

Reinventar formas de dizer, compartilhar e produzir sentidos deve, pois, ser o propósito maior das atividades teatrais numa situação que envolva as anomalias. É nesse âmbito que o poder do teatro como jogo e, sobretudo, a partir de seu inegável valor como espaço de criatividade e improvisação pode atuar de maneira inestimável e, com isso, estimular um novo olhar, que não apenas indulgente ou inclusivista, às potencialidades e características de pessoas consideradas incapazes seja pela deformidade corporal ou por suas condições incomuns de expressão e de comunicação. 


\section{REFERÊNCIAS}

COUNSELL, Colin. Signs of performance: an introduction to twentieth-century theatre. London: Routledge, 1996.

DE LA FALAISE, M. Einstein at the met (an operatic interview). Feb. 1977. Interview. Disponível em: < http://www.robertwilson.com>. Acesso em: 19 jul. 2008.

DE MARINIS, Mario. Dramaturgy of the Spectator. The Theatre Drama Review, New York, v. 31, n. 2 (T114), p. 100-114, Summer, 1987.

DEAFMAN glance. Criação e direção de Robert Wilson. New York: Byrd Hoffman Foundation, 1970.

GALIZIA, Luiz Roberto. Os processos criativos de Robert Wilson. São Paulo: Perspectiva, 1986.

GLUSBERG, Jorge. A arte da performance. São Paulo: Perspectiva, 2003.

GOFFMAN, Erving. A representação do eu na vida cotidiana. Petrópolis: Vozes, 1996. p. 191-217.

LEPOT-FROMENT, Christiane. Introdução. In: Educação especializada: pesquisas e indicações para a ação. Bauru: EDUSC, 1999. p. 9-22.

LULKIN, Sérgio Andrés. Atividades dramáticas com estudantes surdos. Cadernos de Autoria, Porto Alegre, n. 2, p. 51-65, 2000.

MOUNIER, Catherine. Devenir comédien. Les Voies de la Création Théatrale, Paris, n. 9, p. 15-31, 1983.

PAVIS, Patrice. Dicionário de teatro. São Paulo: Perspectiva, 2001.

SCHECHNER, Richard. O que é performance. O Percevejo, Rio de Janeiro, ano 11, n. 12, p. 25-50, 2003. 